\title{
Breeding success of the Himalayan griffon (Gyps himalayensis) in Upper Mustang, Nepal
}

\author{
Kopila Wagley $^{1 *(\mathbb{D})} \mid$ Ravi Prasad Devkota ${ }^{2}$ (I) $\mid$ Krishna Prasad Bhusal ${ }^{3}$ (i) $\mid$ Man Kumar Dhamala ${ }^{1}$ (i) \\ ${ }^{1}$ Central Department of Environmental Science, Tribhuvan University, Kirtipur, Kathmandu, Nepal \\ ${ }^{2}$ Central Department of Zoology, Tribhuvan University, Kirtipur, Kathmandu, Nepal \\ ${ }^{3}$ Bird Conservation Nepal (BCN), Kathmandu, Nepal \\ *Correspondence: wagleykopu7@gmail.com
}

Received: 02 October 2020 | Revised: 01 December 2020 | Accepted: 03 December 2020

\begin{abstract}
Long-term conservation of the species requires the availability of their natural habitat along with all those factors that support their viability. Understanding the breeding success of vulture and different factors affecting it is important to line up species conservation, although very less is known about the reproductive and behavioral ecology of Himalayan griffon (Gyps himalayensis). Therefore, the present study was carried out in Upper Mustang areas of Nepal, a prime habitat for the species. For the determination of the factors influencing breeding success, exploratory research design was used. Identification of vulture's nests was done by direct observation. Altogether 78 nests were identified with $41.02 \%$ breeding success with occupied nest as the primary unit. Almost all the productive nests were found in steep cliffs facing north direction. Nesting sites were located near water sources. Grazing and noise respectively have positive and negative impacts on the breeding success. Developmental activities like road construction, distribution of power lines is proven threat to vulture as per locals' perception and require development activities to be carried out with proper planning
\end{abstract}

Keywords: Conservation, Himalayan griffon, Monitoring, Mustang, Nesting

\section{1 | Introduction}

Vultures are medium to large sized scavenging birds, feeding mostly on the carcasses of dead animals and are found on every continent except Antarctica and Oceania (Del Hoyo et al. 1994). Vultures exhibit crucial ecological role and are regarded as key species for ecosystem services. Vultures are considered to have long life span among bird species with low reproductive rate, which is obligated to feature low fatality rate (Prakash 1999). Adult Himalayan griffons are 103-110cm (41-43inches) long, have a wingspan of $260-289 \mathrm{~cm}$ (102-114inches) across the wings and weigh 8-12 kg (18-26.4lbs). They are the second largest old-world vultures, behind only the Cinereous vulture in size (BirdLife International 2001). Himalayan griffons are distributed from western China, Kazakhstan, Uzbekistan, Kyrgyzstan, Tajikistan, Afghanistan and Pakistan, east through the Himalayan mountain range in India, Nepal and Bhutan, to central China and Mongolia (BirdLife International 2020). This species occurs mainly in mountainous portions of the Himalayas, although juveniles' winter in lowland of the Indian sub-continents (Ali \& Ripley 1968). It is heaviest breeding vulture in Nepal. The breeding season is chiefly January to April or May. Nest is large rough and untidy pad of sticks and rubbish placed on the edge of a cliff, often inaccessible. Share of the sexes in the nesting chores, and period of incubation is about 50 days (Ali \& Ripley 1968). This species is globally Near Threatened because of its moderately rapid population decline over the next three generations owing to the impacts of Diclofenac use in livestock (BirdLife International 2020) and nationally Vulnerable (Inskipp et al. 2016).

A dramatic decline in the vulture number is due to the consumption of carcasses contaminated with residues of Diclofenac following the veterinary treatment of the cattle (Das et al. 2010). Besides, the use of Diclofenac, other environmental changes are also thought to have adverse effect on the population of vultures. Food shortage caused by the burial and burning practice of the carcasses has also contributed for decline in the numbers in some areas (Pain et al. 2003). Other reasons 
believed to be responsible for the decline are decreased breeding efficiency, infectious diseases, general environmental pollution, habitat destruction etc. (Pain et al. 2003, Das et al. 2010). Hence, this study was conducted to assess the breeding success and to analyze the major factors that influences breeding success.

\section{2 | Materials and methods}

\section{1 | Study area}

The study was conducted in Upper Mustang, an area of 2,567 $\mathrm{km}^{2}$, which covers the northern half of Mustang District (Fig. 1) which is the prime habitat of Himalayan griffon (Paudel et al. 2016). The study area belongs to the arid; Trans-Himalayan zone of the Annapurna Conservation Area. Vegetation is of the steppe type and consists of grasslands interspersed with scrub. Cold desiccating winds, a short growing season, low precipitation and cold air temperatures limit the standing biomass produced from the steppe vegetation. Mustang is rich in medicinal and aromatic plants with very high economic and ethno-medicinal values. The majority of local inhabitants of the area are Lama and Gurung who believe on Buddhist culture and there is the sky burial practice. Sky burial is a traditional Tibetan funeral ritual in which the human corpse is exposed to the open area to be eaten by sacred vultures (Bhusal et al. 2020).

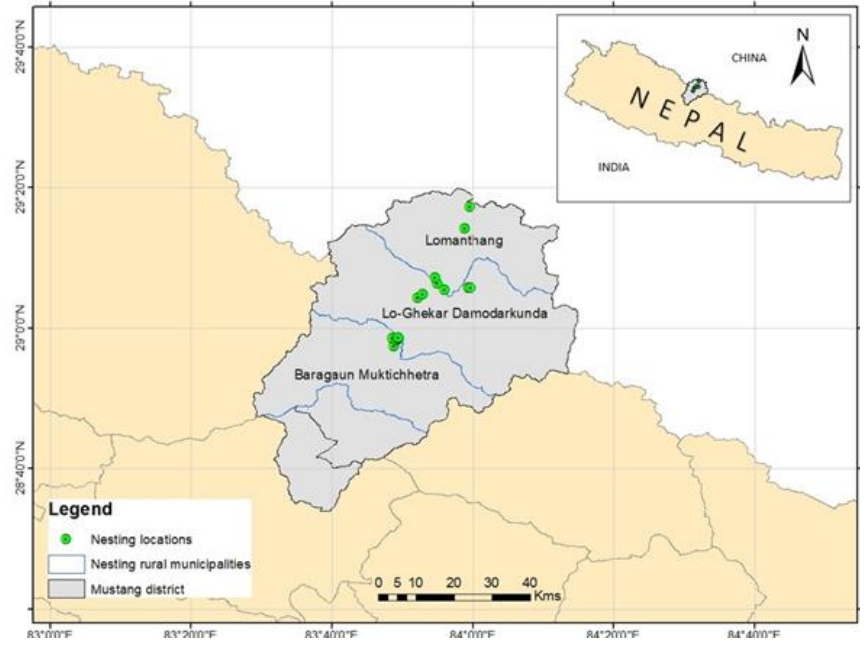

Figure 1. Map showing the locations of the nests in the study area.

\section{2 | Data collection and analysis}

Potential nest locations of Himalayan griffon vulture were identified using existing networks of road and trails. Field visits were done twice i.e. reconnaissance survey in the month of December and productive nest count in the month of April/May.
Observations were made using field binoculars Vikings $\left(8^{*} 42\right)$ and Canon EOS 80D camera. Mapping was done by using Arc GIS. Breeding success was determined by counting nests and nest occupancy. Nests were classified on the basis of Postupalsky (1974) as active nest and occupied nest. An active nest is the one in which eggs had been laid; an occupied nest is the one in which eggs have not been laid but some nest building activity must have taken place. A nest from which a chick fledged is termed as "successful or productive nest". Breeding success was calculated with the given formula

Breeding success $=\frac{\text { Productive nest }}{\text { Occupied nest }} \times 100 \%$

The geographic position and crude height of nests on cliff were recorded with the help of GPS from nearest accessible point. Similarly, other factors influencing the breeding success analyzed in the study are cliff aspect, distance from water sources and settlement, disturbances like noise and road construction, grazing and habitat destruction. All these factors were measured tentatively due to rough and steep terrain such as use of GIS for the distance and qualitative measurement for noise, road construction and habitat destruction i.e. high, medium and low. The factors influencing the breeding success were adopted following the similar but modified method used by Arroyo and Razin (2006) and were analyzed using Generalized Linear Model (GLM).

\section{3 | Results}

\section{1 | Number of nests, location and habitats}

A total of 78 nests were recorded of Himalayan griffon in Upper Mustang. Out of 78 total nests (occupied), 32 nests were found to be productive (Fig. 2). Altogether 13 locations were found to have the colony of Himalayan griffon in different altitude.

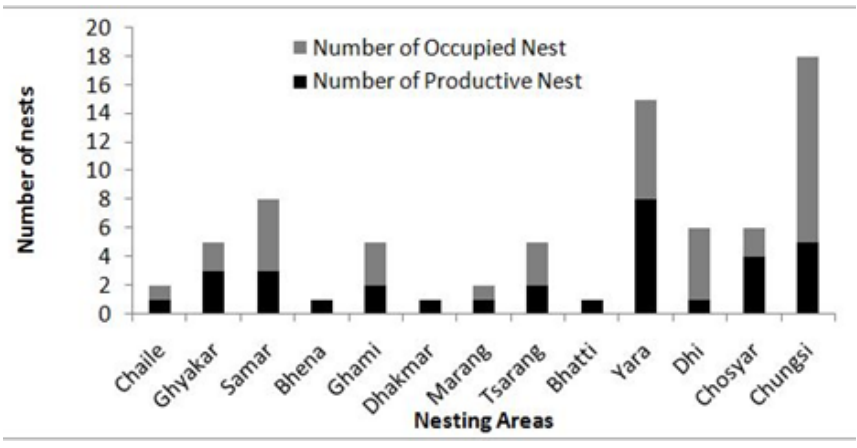

Figure 2. Status of nests and their number in different locations 
All the productive nests were found in the steep cliff ledge (see Annex -1, Photographs 1-3) in an average altitude of $3500 \mathrm{~m}$ $3700 \mathrm{~m}$. Almost all the cliffs were north facing cliffs and the nests were in the cliffs with low sunshine areas. The nests were built in the large, hollow cavity in the rocky terrains. Normally all the roosting sites were very close to the nests. The nests were also near to the water sources and carcass disposal sites along with the sky burial sites. Calculation shows that nesting colonies are very close to the water sources, a slight negative correlation $(r=-0.377)$ existed between the distance of water sources and the presence of active nest number in the locations (Fig. 3).

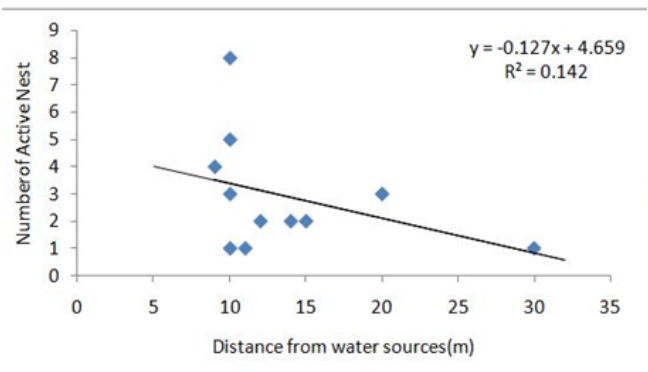

Figure 3. Relationship between distance from water sources $(\mathrm{m})$ and active nests

But the correlation between the distance to settlement and productive nest showed moderate positive correlation $(r=0.41)$. These results shows that that Himalayan griffon prefer to build their nest in those locations where human settlements are nearby (Fig. 4).

\section{2 | Breeding success}

A total of 78 occupied nests were found of Himalayan griffon in the transect survey of study area along with 32 productive nests (Table 1). The breeding success was calculated based on the nest having chicks (productive nest) as it was difficult to collect data of nest having eggs (active nest) due to time constraints, so breeding success was calculated based on occupied nest rather

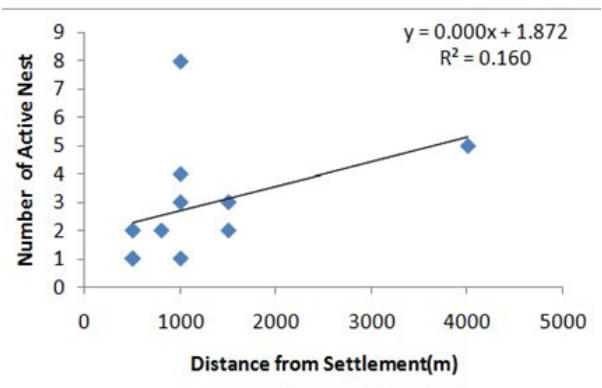

Figure 4. Relationship between the distance from the settlement and number of active nests than active nest due to data lagging the active nest count. The breeding success calculated was $41.02 \%$ (Table1).

Table 1. Breeding success of Himalayan Griffon Vulture in the study area

\begin{tabular}{|c|c|c|c|c|}
\hline S.N & $\begin{array}{l}\text { General } \\
\text { location }\end{array}$ & $\begin{array}{l}\text { Number of } \\
\text { Productive Nest }\end{array}$ & $\begin{array}{l}\text { Number of } \\
\text { Occupied Nest }\end{array}$ & $\begin{array}{l}\text { Breeding } \\
\text { Success }\end{array}$ \\
\hline 1 & Chaile & 1 & 2 & \multirow{14}{*}{$41.02 \%$} \\
\hline 2 & Ghyakar & 3 & 8 & \\
\hline 3 & Samar & 3 & 8 & \\
\hline 4 & Bhena & 1 & 2 & \\
\hline 5 & Ghami & 2 & 5 & \\
\hline 6 & Dhakmar & 1 & 2 & \\
\hline 7 & Marang & 1 & 2 & \\
\hline 8 & Tsarang & 2 & 3 & \\
\hline 9 & Bhatti & 1 & 2 & \\
\hline 10 & Yara & 7 & 15 & \\
\hline 11 & Dhi & 1 & 7 & \\
\hline 12 & Chosyar & 4 & 9 & \\
\hline 13 & Chungsi & 5 & 13 & \\
\hline \multicolumn{2}{|c|}{ Total } & 32 & 78 & \\
\hline
\end{tabular}

\subsection{Factors influencing breeding success}

Based on the model selection of the relation with the breeding success, it is found that relation with habitat destruction was mainly due to Grazing and also the final model selection showed success as the function of grazing. Table 2 shows lowest AIC value for grazing with the $p$ value of 0.011 in $95 \%$ confidence levels. Also, the correlation value of grazing and success is found to be positive i.e. $r=0.478$. Lower the AIC value, the more significant is the variable for the breeding success.

Thus, final model selection showed success as the function of grazing through which it can be concluded that grazing has effect on the breeding success. Grazing here defines the grazing land, an open space which holds a good number of dead animals and acts as source of food to the species. Similarly, other variable like noise (vehicle movement and road construction) also plays a role.

Table 2. Generalized Linear Model with AIC values

\begin{tabular}{|l|l|l|}
\hline $\mathbf{S N}$ & Variables & AIC value \\
\hline $\mathbf{1}$ & $\begin{array}{l}\text { Altitude+ Slope Aspect +Distance to settlement } \\
\text { +Distance to water+ Grazing }\end{array}$ & 126.49 \\
\hline $\mathbf{2}$ & $\begin{array}{l}\text { Altitude +Distance to settlement +Distance to water+ } \\
\text { Grazing }\end{array}$ & 118.97 \\
\hline $\mathbf{3}$ & $\begin{array}{l}\text { Altitude+ Slope Aspect +Distance to settlement + } \\
\text { Grazing }\end{array}$ & 117 \\
\hline $\mathbf{4}$ & Altitude + Grazing & 115.02 \\
\hline $\mathbf{5}$ & Grazing & 113.09 \\
\hline
\end{tabular}


Establishing the relationship between breeding as a function of noise showed a negative correlation $(r=-0.61)$ which signifies that breeding success is less in noisy (disturb) areas.

\section{4 | Discussion}

The study results reveal that almost all the nests were near to the human settlement showing positive correlation but are not significant. Similar study by Ghimire (2016) found that vultures breeding was found in all regions with human disturbances having both high and low frequency which proves that human disturbances are tolerable to the species. Poirazidis et al. (2007) also found that anthropogenic disturbance did not seem to be an important factor in nest selection of the raptors as many of them can tolerate a low intensity and short duration of human disturbance near their nests. Thus, taking several researches in consideration it can be concluded that moderate kind of disturbance is tolerable to vultures and are not affected by medium level of disturbance.

The study area holds a large number of nests that were found in the cliffs located near to the water sources like streams, rivers and rivulets because river banks are good areas for the disposal of dead bodies of animals which served a good meal to the species increasing the food viability. Not only this, both active and occupied nest present near the water sources enables the species and their young ones with easy access to water after feeding on the carrions. Thakur and Narang (2012) study also revealed that most nest sites were found with some sources of water nearby. Ghimire (2016) in the study also found the nests in forest edge nearby the water sources. Ramkrishna et al. (2014) also confirmed through the study, water as an important need for all living things and found it to be true in case of nesting of vultures too.

The number of productive nests with higher frequency was found in the cliffs near to the grazing areas. The result also shows a significant influence of grazing areas in breeding. This may be probably due to the food availability in the grazing lands because domesticated animals that are dead during herding or in home are left in this open space providing a good meal to this species. Lu et al. (2009) through his research found that open meadow habitat has the highest abundance of griffon which was followed by alpine shrub and forest habitats.

Only three carcasses were observed which were disposed near the water sources and the result from questionnaire survey revealed that migration and decrement in the sky burial practices shows the limitation of food availability. Though, food shortage does not have direct impact in the breeding success but may prevent vulture populations from returning to pre-decline numbers (Thiollay 2007). Thus, lower availability of food during breeding period may also be the cause for the nest failure. Pain et al. (2003) also concluded that probable decrease in the avian scavengers is mainly due to loss of wild ungulates and free ranging domestic cattle creating a narrow feeding niche. From direct observation, habitat destruction, lack of carcasses and human disturbances primarily developmental activities in breeding sites were seen as major threats to the vulture. Similar threats to the vulture were seen and are functioning for declination of species which was found by Bhusal (2011) and Chhetri (2014).

\section{5 | Conclusions}

The breeding status of Himalayan griffon was estimated with good number of productive nests. Breeding success of this species based on occupied nest as a primary unit was found out to be relatively good. Nests were mostly found on stiff cliffs facing the North Slope and with low sunshine areas, near river banks and other water sources and near human settlement. Breeding success was found significant with grazing and altitude. Similarly, noise is also negatively correlated to the number of productive nests showing that noise also affects the breeding success. Proper grazing management including proper planning in development activities will hold keys to the breeding success of the vulture in Upper Mustang in the future.

\section{Acknowledgements}

First author would like to dedicate this publication to her supervisor late Dr. Man Kumar Dhamala. We would like to express our special gratitude to Bird Conservation Nepal (BCN) for financial support to our work. We are also thankful to Department of National Parks and Wildlife Conservation (DNPWC), Annapurna Conservation Area Project (ACAP) and the people of Upper Mustang.

\section{Authors' contributions}

Wagley, K. conceptualized and designed the study, collected, analyzed and interpreted the data, wrote the manuscript; Dhamala, M. K. supervised research work, analyzed the data and wrote the manuscript; Devkota, R. P. collected the data and 
contributed in manuscript; Bhusal, K. P. contributed in designing the study and finalizing the draft.

\section{Conflicts of interest}

Authors declare no conflict of interest.

\section{ORCID}

Kopila Wagley (iD https://orcid.org/0000-0002-9393-6443

Ravi Prasad Devkota (iD https://orcid.org/0000-0002-7294-2908

Krishna Prasad Bhusal iD https://orcid.org/0000-0002-2259-1513

Man Kumar Dhamala iD https://orcid.org/0000-0003-0687-6946

\section{References}

Ali, S. and Ripley, S.D. 1968. Himalayan griffon Vulture. Handbook of the Birds of India and Pakistan together with those of Bangladesh, Nepal, Bhutan and SriLanka. Compact edition, Sponsored by the Bombay Natural History Society, Delhi, Oxford University Press, Oxford New York, 1:302-304.

Arroyo, B. and Razin, M. 2006. Effect of human activities on bearded vulture behaviour and breeding success in the French Pyrenees. Biological Conservation 128(2):276-284.

https://doi.org/10.1016/j.biocon.2005.09.035

BirdLife International (2001).Threatened Birds of the World. BirdLife International and Lynx Editions, Cambridge and Barcelona.

BirdLife International 2020. Species factsheet: Gyps himalayensis. http://www.birdlife.org Accessed on 22/11/2020.

Bhusal, K. P., Chaudhary, I. P. and Rana, D. B. 2020. Vultures and People: Some Insights into an Ancient Relationship and Practice of Sky Burial Persisting in Trans-Himalayan Region of Nepal Vulture Bulletin 9:43-45.

Bhusal, K. P. 2011. Population status and breeding success of Himalayan griffon, Egyptian Vulture and Lammergeier in Gherabhir Arghakhanchi, Nepal. MSc Thesis, Central Department of Zoology, Tribhuvan University, Kirtipur, Kathmandu, Nepal.

Chhetri, J. 2014. Status of White-rumped vulture (Gyps bengalensis) and role of the vulture restaurants in conservation of the vultures in Rupandehi district. MSc Thesis, College of Applied Sciences, Kathmandu, Nepal.

Das, D., Cuthbert, R. J., Jakati, R. D. and Prakash, V. 2011. Diclofenac is toxic to the Himalayan Vulture Gyps himalayensis. Bird Conservation International 21(1):72-75. https://doi.org/10.1017/S0959270910000171

Del Hoyo, J., Elliott, A. and Sargatal, J. 1994. New world vultures to guineafowl. Handbook of the Birds of the World. Vol. 2. Lynx Edicions, Barcelona.
Ghimire, B. 2016. Breeding status of White-Rumped Vulture Gyps bengalensis in Rupandehi District, Nepal. MSc Thesis, Tribhuvan University, Kirtipur, Kathmandu, Nepal.

Inskipp, C. H. S., Baral, S., Phuyal, T.R., Bhatt, M., Khatiwada, T., Inskipp, A. et al. 2016. The status of Nepal's Birds: The National Red List Series. Zoological Society of London, UK.

Lu, X., Ke, D., Zeng, X., Gong, G. and Ci, R. 2009. Status, ecology, and conservation of the Himalayan griffon Gyps himalayensis (Aves, Accipitridae) in the Tibetan Plateau. AMBIO: a Journal of Human Environment 38(3):166-173. https://doi.org/10.1579/0044-7447-38.3.166

Pain, D. J., Cunningham, A. A., Donald, P. F., Duckworth, J. W., Houston, D. C., Katzner, T. et al. 2003. Causes and effects of temporospatial declines of Gyps vultures in Asia. Conservation Biology 17(3):661-671. https://www.jstor.org/stable/3095223

Paudel, K., Galligan, T., Amano, T., Acharya, R., Chaudhary, A., Baral, H. S. et al. 2015. Population trends in Himalayan griffon in Upper Mustang, Nepal, before and after the ban on diclofenac. Bird Conservation International 26:286-292. https://doi.org/10.1017/S0959270915000192

Poirazidis, K., Goutner, V., Tsachalidis, E. and Kati, V. 2007. Comparison of nest site selection patterns of different sympatric raptor species as a tool for their conservation. Animal Biodiversity and Conservation 30(2):131-145. https://www.raco.cat/index.php/ABC/article/view/76077

Postupalsky, S. 1974. Raptor Reproductive Success: Some Problems with Methods, Criteria and Terminology. Management of Raptors Raptor Research Report No. 2. Vermillion, South Dakota.

Prakash, V. 1999. Status of vultures in Keoladeo National Park, Bharatpur, Rajasthan, with special references to population crash in Gyps species. Journal of the Bombay Natural History Society $96: 365-378$. https://www.biodiversitylibrary.org/page/48583052

Ramakrishnan, B., Kannan, G., Samson, A., Ramkumar, K. and Ramasubramanian, S. 2014. Nesting of White-rumped Vulture (Gyps bengalensis) in the segur plateau of the Nilgiri North Forest division, Tamilnadu, India. Indian Forester 140(10):10141018. http://www.indianforester.co.in

Rasmussen, P. C. and Parry, S. J. 2000. On the Specific Distinctness of the Himalayan Longbilled Vulture Gyps (indicus) tenuirostris. Abstract, $118^{\text {th }}$ Stated Meeting of the American Ornithologists Union, Memorial University of New Found land, USA, p 64.

Shrestha, T. K. 2001. Himalayan griffon. Birds of Nepal. Field Ecology, Natural History and Conservation 2:537-538.

Thakur, M. L. and Narang, S. K. 2012. Population status and habitatuse pattern of Indian White-backed Vulture (Gyps bengalensis) 
in Himachal Pradesh, India. Journal of Ecology and the Natural Environment 4(7):173-180. https://doi.org/10.5897/JENE11.103 Thiollay, J. M. 2007. Raptor population decline in West Africa. OstrichJournal of African Orinthology 78(2):405-413.

https://doi.org/10.2989/OSTRICH.2007.78.2.46.126

\section{Cite this article as:}

Wagley, K., Devkota, R. P., Bhusal, K. P. and Dhamala, M. K. 2020. Breeding success of the Himalayan griffon (Gyps himalayensis) in Upper Mustang, Nepal. Nepalese Journal of Zoology 4(2):95-100. https://doi.org/10.3126/njz.v4i2.33891

Annex 1. Photoplates showing the active nests and nesting sites of Himalayan griffon
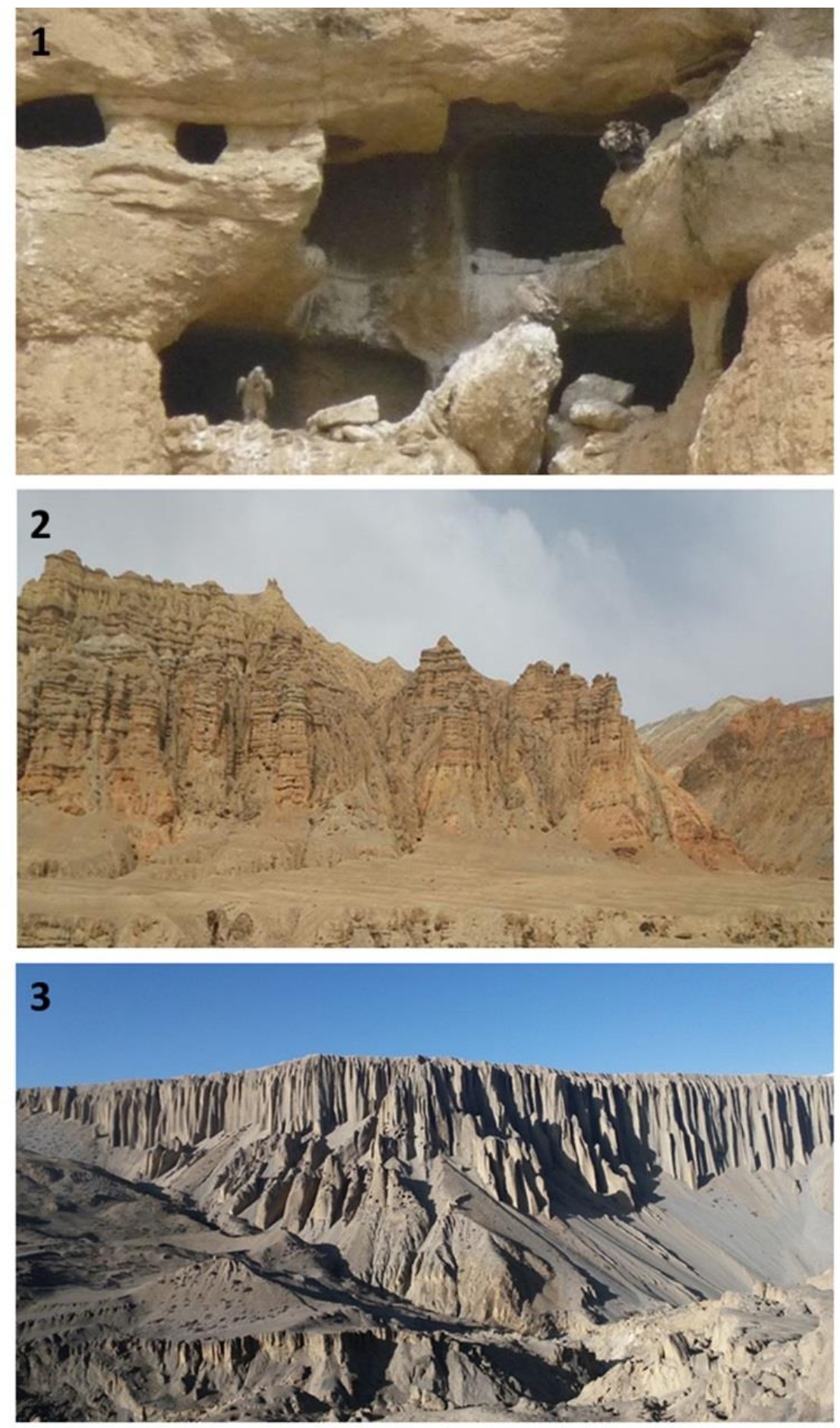

Photoplates 1-3. Photo-1: Active nest of Himalayan Griffon in Upper Mustang, 25 March 2018; Photo-2: Nesting sites of Himalayan Griffon near Jhong Cave of Upper Mustang, 25 March 2018; and, Photo-3: Nesting sites of Himalayan Griffon in Yara village of Upper Mustang, 03 April 2018. 